August 26th. He was much improved. The restlessness had disappeared. The fits were gradually decreasing in number and severity. He had regained the entire use and sensation in his arm and leg.

September 4th. All that remained now was slight occasional twitchings of the left side of the face. He was much stronger, and went out daily. $\mathrm{He}$ was ordered to take small doses of sulphate of zinc and extract of henbane three times a day.

October 20th. He had now lost all traces of the twitchings, excepting very occasionally, and then only very slight. He has perfect use of his arm and leg.

October 27th. He returned to his situation, as he said, " as well as ever he was".

\section{PATHOLOGICAL AND PRACTICAL RESEARCHES ON THE VARIOUS FORMS OF PARALYSIS.}

By Edward Meryon, M.D., F.R.C.P. [Continued from page 4j1.]

Paralysis froji Dislocations and Fractures of the VERTEBR.E.

THE functional disturbarice of the spinal cord which at tends almost all cases of dislocations and fractures of the vertebræ imparts an interest to such particular injuries, which the same accidents to other bones do not possess.

The shortness of the vertebræ, the intricate manner in which they are interlocked, the large surfaces by which their bodies are connected, and the small amount of motion admitted between any two of them, render it almost impossible that either dislocation or fracture can occur without considerable violence and mischief being done to the spinal marrow; and yet we do occasionally hear of fractured spines without paralysis, but they are exceptional cases.

Paralysis of every part of the body which is supplied with nerves proceeding from the spine below the seat of injury is the all-important symptom, and in almost every case it will be found that retention of urine and difficult defecation exist also. The former of these symptoms, however, is not dependent on a palsied state of the muscular fibres which surround the bladder, for that organ empties itself perfectly when a catheter is introduced. The detrusor urinæ is a voluntary muscle, and its loss of power would in some degree account for the difficult micturition; and it is chiefly to the loss of voluntary relaxation of muscles which surround the urethra and the rectum to which the symptoms in question are due. Like all other voluntary muscles of the body, they are under the influence of the spinal cord, and, as we have seen in most of the cases thus far recorded, retention of the excretions results from a severe injury or division of the cord. Incontinence is a common symptom when disease of the cord comes on gradually. It implies either irritation of the cord or of the bladder, in which latter case it is simply a reflex action, and as such, appears when the sphincter muscles of the bladder and rectum have lost their contractility shortly before death takes place.

Two instances of dislocation are contained in the Leçons Orales of Baron Dupuytren (On the Injuries and Diseases of Bones. Translated and edited by F. Le Gros Clark. Sydenham Society.) These typify all dis. locations at the lower part of the cervical region, and tend to illustrate the fact, as stated by that illustrious surgeon, that the cause of death is, apparently, "the upward extension of disorganisation of the spinal cord, so that the origin of the phrenic nerves is ultimately in. volved, and death takes place from asphyxia."
MM. Hamon and Mercier have related two cases of fractured sacrum, in each of which, together with partial paralysis of the lower extremities, there was retention of urine and fæces. So also in a patient of Dupuytren's, who threw himself from a third story window. "There was deformity and abnormal mobility near the lumbar region. The paralysis did not at first extend above the lower parts of the thighs, but the bladder and rectum were included. There was a temporary improvement, but soon the paralytic condition involved the whole of the lower limbs; an extensive slough formed on the sacrum, and the patient sank, preserving his intellectual faculties to the last. The spinal cord was found more volumiuous than natural, especially at its lower part. Opposite the tenth dorsal vertebra was a cyst filled with pus, and formed in part by the medullary substance reduced to a fluid consistence; the body of the second lumbar vertebra was fractured" (Ibid., p. 365.)

The subject of the following case, also described by Dupuytren (Ibid., p. 358.9), gives us some idea of the time required for the restoration of nerve-fibre after it has suffered solution of continuity.

Case. "Charles Millié, aged 21, carman, was admitted into the Hotel Dieu in 1825, with paralysis of the bladder and extremities, caused by a fall on the neck. The paralytic condition was more marked on the left side than on the right, and in the lower than in the upper extremities. After two months and a balf of en. tire rest, combined with blood-letting from the arm, as well as by cupping and leeches, he was convalescent, and quitted the hospital with only slight weakness in the left leg, and the head a little bowed forwards.

"In spite of injunctions to be very cautious in taking exercise, he undertook a long walk, and whilst out was attacked with paralysis; he fell down, and remained in the open air all night. When convesed to the Hotel Dieu on the following day, the paralytic condition was much more complete than on the former occasion, involving the lower extremities, which were entirely powerless and insensible, and also the arms from the shoulders to the hands. At the lower part of the neck there existed a pain which extended to the left shoulder; neither bladder nor rectum acted.

"The patient was bled twice and the catheter passed. Some days afterwards, he was affected with spasmodic contractions of the limbs and bladder, and the catheter was no longer required. A moxa was applied between the shoulders, but without benefit; the skin over the sacrum and trochanters began to slough, diarrhœa set in, and the patient sank exhausted thirty-four days after the fall.

" On examining the spine, a fracture through the lower part of the body of the fourth cervical vertebra was found ; it extended obliquely downwards and forwards, but the parts were prevented from being displaced by the articular processes. The left transverse and articular processes of the fifth vertebra were fractured, so as to permit the fourth to slip forward and compress the cord at this point. The intervening fibro-cartilage between the fourth and fifth vertebræ had disappeared; and along the line of fracture in front of their bodies was an osseous deposit, resembling callus; which itself presented a fissure, as if consolidation had taken place, but the parts had again yielded to violence.

"Opposite the point of compression the cord exhibited an annular constriction, abrupt and well marked, and very analogous to that presented by the intestine in some cases of strangulated hernia. When incised longitudinally at this spot, the colour and consistence of the cord were found altered to a brownish hue, and the density and firmness of fibrous tissue; a small circum. scribed spot, about a line in extent, was especially characterised in this way. The membranes were also more adherent here than elsewhere. It was inferred that the seat of this peculiar change was that of the original 
lesion, and that the above appearance constituted a true cicatrix of the spinal marrow."

In another instance, the details of which are contained in the Rapport de la Société de Chirurgie (L'Union Médicale, 1860 , p. 525), about the same period of time was required for restoring the integrity of the spinal cord after an incised wound.

CASE XXv. A boy, aged 15, received a wound from a cutling instrument in the back, which penetrated between the tenth and eleventh dorsal vertebræ, and probably divided the right half of the spinal marrow. There was complete paralysis of motion, and incomplete loss of sensibility of the right thigh and leg. The patient made a good recovery, and, at the end of two montbs, was able to walk four or five miles. A remarkable symptom in this case, which has been often noticed before, was the quantity of cerebro-spinal fluid which escaped from the wound during the first twelve days after the receipt of the injury.

A somewhat similar, though less successful case is reported by Herr Schwanderer, in which a punctured wound was inflicted in the spinal marrow between the second and third dorsal vertebræ. There was paralysis of the right foot and leg, shortness of breathing, and involuntary discharges of fæces and urine. The foot remaiaed partially paralysed.

The next case which fell under the observation of Mr. Belcher of Burton-on.Trent, is interesting, not only as illustrative of fractured spine generally, but as an example of reflex action induced by the first shock given to the spinal marrow. The details are contained in the British Medical Journal for November 22nd, 1862, pp. 531-2.

In all these accidents there is so definite a correspondence between the extent of paralysis and the seat of the injury that the diagnosis is seldom difficult; and with the additional evidence afforded by the deformity, the abnormal mobility, the crepitus, and the absence of cerebral symptoms, the nature and measure of the mischief may be determined with tolerable certainty. It should be remembered, however, that concussion of the spine, without either dislocation or fracture, has been known to produce paralysis; and Dupuytren has as. cribed some cases of diseased cervical ligaments which have led able practitioners into error (Op.cit., pp. 346.9).

But when either dislocation or fracture of the first or second cervical vertebra involves the phrenic nerve in the lesion which destroys the function of the other nerves which associate the muscles of the chest in the act of respiration, there is no time given for diagnosis. In the cases just described, a patient may drag on a painful existence for a time, but when such an injury is inflicted on the cord at the base of the medulla oblongata death is the immediate result-another breath is not drawn. Two instances of this are recorded by Sir Charles Bell ("On the Nerves which Associate the Muscles of the Chest in the actions of Breathing, Speaking, and Expression." Philosophical Transactions, 1822, $\mathrm{p}$ $302)$.

In both cases, the injury of the medulla oblongata arrested the act of respiration on the instant of its occurrence. Not only is the attempt to reduce either dislocation or fracture inexpedient, but it is positively dangerous; for the force required to effect the desired object would necessarily implicate the spinal cord in the extension, and intensify the mischief which compres sion may have set up. Therefore, with whatever reluc tance we may feel, yet must we regard these injuries a incurable and mortal.

If, however, as sometimes happens from gun-sho wounds, the spinous process only of a vertebra be frac tured the mischief is not very serious. I remember to have seen a case in which the spinous process and the posterior portion of the arch of one of the lower cervical vertebre was shot away so that the theca of the cord was exposed. The subject of the accident was an officer, who received the wound in the Crimean war. When he arrived in England the external wound had healed, butes pressure over the part produced numbness and a senseo of heaviness of the arms. By wearing a metallic shield over the part he suffered no great inconvenience.

Perfect quiet on the back is the best remedy in alf fractures and dislocations of the vertebral column; but 8 great care is necessary to protect the paralysed and in sensible surface from bed-sores. Active treatment mayes be necessary to subdue local inflammation; and if muchflatulent distension of the abdomen exist, a warm purgative enema may be given. If requisite, the urine must be drawn off by a catheter. In cases of diseasedw ligaments of the spine issues are of great service.

It will be observed that, I have endeavoured to illus $-\frac{O}{3}$ trate the relationship between the symptoms of diseaseand the anatomical structure of the parts on which those symptoms depend. This course, I venture to think, if more useful than the search after rare ard exceptionalo cases in which, supposing the post mortem examinationso to have been perfectly conducted, we are compelled to admit the marvellous and inexplicable nature of the diso ease.

The most extraordinary that $I$ remember to have read of is contained in the Journal de Chirurgie (tome iv, p $137,1792)$. The subject, J. P. Ripert, aged 21, was ad mitted into the Hôtel Dieu on August 10th, 1792, in consequence of a gun.shot wound just below the inferion angle of the scapula, and which had occasioned effusion into both sides of the thorax. He survived the wound twenty-six hours, during which no other symptoms than those of effusion manifested themselves. He voidefo his urine freely, had no paralysis of the inferior extremic ties, but, on the contrary, continued to move them in an agitated manner until he died.

On tracing the course of the ball after death, it was seen to have penetrated the chest between the eightr and ninth rib, to have traversed the inferior lobe of the right lung, thence through the right side of the bod? of the tenth dorsal vertebra into the vertebral canab where it had entirely divided the spinal marrow. From the spinal canal it passed into the left cavity of the thorax, which, like the right, was found full of blood? and carried out with it a portion of the inferior lobe ot the left lung between the seventh and eighth ribs, neav their angles.

Two cases are reported in the Archives Générales de Médccine (Memoire sur quelques alterations de lo Moelle Epinière dont les observations principales on été recueillies à la Clinique et sous les yeux de MI. le Professeur Bougon, tome vii, p. 329). The subject of one was a soldier, who had received a sword thruse through the posterior part of the twelfth dorsal verte 3 bra, between the spinous and oblique processes. Thब wound passed throngh the spinal cord, the point of the sword extending to the right side of the eleventh dorsad vertebra, whence it was extracted after death. Yet the man marched eighty leagues after the infliction of this wound; and Velpeau vouches for the accuracy of the details of the case.

The other was a tailor, aged 1\%, who had diseasce vertebræ and spinal curvature, together with a fistulous abscess in the left thigh. He died without any paraly sis, yet were there two vertebræ and the lower half of the lumbar swelling of the cord absolutely destroyed.

The case reported by my late friend, Mr. Stanley, to the Royal Medical and Chirurgical Society, is so genes rally krown that I ought, perhaps, to apologise for quoting it. The disease was not the result of an accident but came on spontaneously and increased progressively Loss of motion became complete throughout the wholg extent of each lower extremity, but in no part was there defect of sensibility; scratching, pricking, or pinching being attended by sensations as acute as ever. 
On examining the body, no disease was found in the anterior columns of the cord, but the whole of the posterior from the pons to the lower end of the cord were changed in colour and consistence. (London Medical Gazette, February 7th, 1840.)

An exactly similar case has been reported by $\mathrm{Dr}$. Budd. Considering the marvellous uniformity which exists in the anatomical structure of every organ, and the special function of each individual tissue; considering, too, the unvaried results of experiments when performed on the same parts of the nervous system, in the same manner, and under precisely the same conditions, in the lower animals, I am more disposed to believe in the incomplete examination of pathologists than in any freaks of nature. How seldom, for instance, is the grey substance of the cord adequately examined during a post mortem investigation; and yet there it is-if the starting point of every nervous fibre contained in the auterior roots of nerves mean anything-that we should look for an efficient cause, for there it is that every muscular motion must originate. Then, again, to what false conclusions may the varving conditions of the spinal marrow lead us when it is examined after death! It has been already observed that, no part of the animal body undergoes such rapid changes as does the nervous systern when its vital action has once ceased; and yet low prone are we to infer that as we find it, such was its state at the last moment of life; and, thereupon to dilate on the discordance between its physiological action and its morbid condition.

Lateral Curvature of the Spine produced by Paralysis of the Muscles of Respiration. Before I leave this part of my sulject, a few observations on the ingenious theory of Dr. Stromever (Ueber Paralyse der Inspirations-MIus7icln. Hannover, 18:36), which attributes to partial paralysis of the muscles of respiration the ordinary form of scoliosis, may not be considered out of place.

The dependence of the muscular tissue for its healthy contractile power upon a constant and adequate supply of arterial blood is too universally admitted to require being insisted on here. On this axiom, Dr. Stromeyer conceived a doctrine which is worthy of our best consideration, seeing that it may suggest means both of prevention and cure, available for the purposes of everyday practice.

The accessory muscles of respiration possess two distinct functions, the one appertaining to voluntary motion, the other to respiration; and these functions are dependent or two distinct sets of nerves.

The sterno-cleido-mastoideus and trapezius muscles have nerves going to them from the cervical plexus for the purpose of moving the head and shoulders, whilst they also receive a special nervous influence from the spinal accessory nerve.

The scrratus magnus anticus, too, has nerves from the dorsal plexus, because it has to assist in the mo. tions of the body in locomotion; but it receives also the so-called external respiratory nerve, which is, as Sir Charles Bell first called it, the counterpart of the internal or phrenic nerve.

To make this part of Dr. Stromeyer's theory more intelligible, I will take the liberty of transcribing Sir Charles Bell's oliservations on these three muscles.

1. "The stcrno-cleido mastoideus, by its attachment to the sternum, and to the clavicle, raises or heaves the chest. The usual description of the muscle is to con sider it as a muscle of the head, the lower attachments being the origins; but when the head is fixed, it becomes a muscle to raise the chest, and its operation is evident in all excited states of respiration, in speaking, and stil more in singing, coughing, and sneezing. But there is something necessary to the full effect of this muscle on the chest, for otherwise it will be a muscle of the head, and not of the chest. This leads us to the next muscle."
2. "The trapezius must fix the head or pull it backwards before the mastoid can act as a respiratory muscle; and how they are combined we shall presently see. The position of the head of the asthmatic during the fit, as well as the posture of the wounded or the dying, prove the influence of the upper part of the trapezius in excited respiration; that is to say, when the shoulders are fixed, this muscle, usually described as a muscle of the superior extremity, becomes a muscle fixing the head." "The trapezius has a still more powerful and important influence in respiration when the action rises above the ordinary condition, and that is by drawing back the scapula, to give recessary effect to the action of the serratus magnus on the ribs."

3. "The serratus magnus anticus being extended over the whole side of the chest, and attached in all the extent from the second to the eighth rib, is very powerful in raising the ribs and holding out the margins of the chest, which would be otherwise drawn in by the diaphragm; and to this effect the intercostal muscles alone would be insufficient in the high or excited state of respiration. But it cannot exert this power independently of the trapezius, since, without the combination explained above, its force would be exerted on its more common office of moving the scapula and not the ribs. Unless the scapula be fixed, or pulled back by the trapezius, the serratus is not a muscle of respiration."

"In this manner do these three powerful muscles hold together in their action, combining with the diaphragm to enlarge the cavity of the chest in all its diameters. These external muscles do not interfere with the gentle actions of breathing. But if the apparatus of respiration is to be employed in any excess of action, in passion, in dying, in speaking, singing, coughing, yawning, etc., these become powerful instruments.

Now, it is to the defective energy of these accessory muscles, that Dr. Stromeyer attributes scoliosis or lateral curvature of the spine.

The action of the serratus is to keep the ribs stretched outwards, backwards, and upwards-to raise them and hold out the margins of the chest; but, when from any cause as in individuals whose exercise is inadequate to the maintenance of a healthy circulation and vigorous muscular action, the serrati fall into weakened and diminished action, their opposing muscle, the diaphragm, draws the sides of the chest downward and inward, and, as the left serratus is generally less active than the right, there is a resulting concavity of the left side of the chest. This begins immediately under the axilla, and no sooner is the equilibrium disturbed than the serratus of the concave side acts under unfavourable circumstances. Thus the more it is enfeebled the more does the diawhragm pull in the ribs of that side, and the trapezius of the arched side comes to assist in the distortion of the bony framework of the entire trunk.

It must be admitted that the theory is exceedingly in. genious, and it has the incidental advantages of harmonising with the most recent investigations on the influence of the vaso motor nerves on the functions of respiration and nutrition; and of indicating a system of treatment the most likely to improve the general health by increasing the tone of the inspiratory muscles.

Advance of Nations. Those nations are furthest advanced intellectually and physically which are most thoroughly composite in their character." Dr. Hammond remarks, "that numerous examples of the improvement of races have been furnished in the history of the world ;" and that " in the United States we have the most striking example of all. Who can doubt that the activity both of mind and body, the ceaseless energy, the superb physical development of the people, are due to the commingling of the blood of all the nations of Europe? To be an American is to be a cosmopolitan." 